\title{
REVITALISASI NILAI ETOS KERJA DALAM HADIH MAJA SEBAGAI BAHAN AJAR PENDIDIKAN KARAKTER
}

\author{
Mohammad Harun ${ }^{1}$, Husaini Ibrahim ${ }^{2}$, Denni Iskandar ${ }^{3}$ \\ ${ }^{1}$ Pendidikan Bahasa Indonesia, FKIP Universitas Syiah Kuala \\ Email: deniiskandar75@yahoo.com \\ ${ }^{2}$ Pendidikan Sejarah \\ Email: sainimalem@yahoo.com.my \\ ${ }^{3}$ Pendidikan Bahasa Indonesia \\ Email: deniiskandar75@yahoo.com
}

\begin{abstract}
This study aimed to identify and interpret the basic principles and characteristics of values of Acehnese people'swork ethos based on hadih maja (Acehnese proverbs) as a learning material in character education. The type of study used was ethnography. The data sources consisted of documents and informants in six regencies/cities in Aceh. The techniques of data collection included document review and interview technique. The data of hadih maja were analyzed with descriptive qualitative technique. The result of the study showed that hadih maja consisted of 7 basic principles and 23 characteristics of values of Acehnese people's work ethos that could be included as learning materials in character education. The learning materials were aimed to be able to be used to improve the work ethos of young generation that made them competitive in working world. The implementation of character education based on hadih maja emphasized the importance of exemplary elements along with the efforts to create conducive social environment for learners, either in family, school, or in society.
\end{abstract}

Keywords: revitalization, work ethos, hadih maja, character education

\begin{abstract}
ABSTRAK
Penelitian ini bertujuan mengidentifikasi dan menafsirkan prinsip-prinsip dasar dan karakteristik nilai-nilai etos kerja orang Aceh berbasis hadih maja sebagai bahan ajar pendidikan karakter. Jenis penelitian yang digunakan adalah etnografi. Sumber data terdiri atas dokumen dan informan di enam kabupaten/kota di Aceh. Teknik pengumpulan data terdiri atas teknik kaji dokumen dan wawancara. Data hadih maja dianalisis dengan teknik deskriptif kualitatif. Hasil penelitian menunjukkan bahwa hadih maja mengandung 7 prinsip dasar dan 23 karakteristik nilai etos kerja orang Aceh yang dapat dijadikan sebagai bahan ajar pendidikan karakter. Bahan ajar dimaksud dapat digunakan untuk meningkatkan etos kerja generasi muda sehingga kompetitif dalam dunia kerja. Pelaksanaan pendidikan karakter berbasis hadih maja menggarisbawahi pentingnya unsur keteladanan yang disertai dengan upaya-upaya untuk mewujudkan lingkungan sosial yang kondusif bagi para pembelajar, baik dalam keluarga, di sekolah, maupun dalam masyarakat.
\end{abstract}

Kata Kunci: revitalisasi, etos kerja, hadih maja, pendidikan karakter

\section{PENDAHULUAN}

Penelitian ini menelaah etos kerja orang Aceh dalam bingkai pendidikan karakter ditinjau dari perspektif hadih maja. Hadih maja atau ungkapan bijak merupakan kristalisasi pemikiran dan kearifan lokal (local genius dan local wisdom) etnis Aceh yang mengandung nilai religius, filosofis, etis, dan estetis. Kajian difokuskan pada persoalan prinsip dasar dan karakteristik nilai etos kerja yang berkarakter.

Hadih maja merupakan puisi lisan Aceh yang identik dengan ungkapan tradisional atau puisi rakyat (Harun, 2006) sebagaimana juga dimaksudkan Brunvand (1968:38) dan Danandjaja (1997:21-22) tentang puisi lisan. Hadih maja sering juga diartikan sebagai kata atau kalimat berhikmat (Hasjmy dalam Ara, dkk., 1995:539) atau nasihat dan petuah hidup nenek 
moyang yang "mengandung nilai-nilai moral dan pendidikan keagamaan" (Ali dalam Talsya, ed. 1994:199), serta nilai etis, dan nilai filosofis (Harun, 2006). Kata hadih berasal dari bahasa Arab hadits yang berarti tindakan, ucapan, dan diam Rasulullah Muhammad saw mengenai sesuatu. Istilah hadih tersebut kemudian menjadi salah satu dimensi hidup masyarakat Aceh. Akan tetapi, jauh sebelum Islam masuk ke Aceh, orang Aceh sebenarnya sudah memiliki sumber nilai dan sumber hukum dalam kebudayaan mereka. Salah satunya adalah narit maja yang kemudian berganti nama menjadi hadih maja.

Hasil bacaan awal menunjukkan bahwa dalam hadih maja terdapat banyak etos kerja. Etos berasal dari bahasa Yunani ethikos, yang berarti moral atau menunjukkan karakter moral. Dalam bahasa Yunani kuno dan modern, etos berarti keberadaan diri, jiwa, dan pikiran yang membentuk seseorang. Dalam Webster's New Word Dictionary, 3rd College Edition (diunduh Februari 2015) dikemukakan bahwa etos berarti kecenderungan atau karakter; sikap, kebiasaan, keyakinan yang berbeda dari individu atau kelompok. Etos berhubungan juga dengan etika, seperti rajin, bekerja keras, berdisiplin tinggi, menahan diri, ulet, dan tekun. Dalam Kamus Besar Bahasa Indonesia (Depdiknas, 2003:309310) disebutkan bahwa etos berarti pandangan hidup yang khas dari suatu golongan sosial, sedangkan etos kerja berarti semangat kerja yang menjadi ciri khas dan keyakinan seseorang atau suatu kelompok.

Konsep etos kerja berkarakter yang tertuang dalam hadih maja tidak selalu teraplikasikan dalam kehidupan sehari-hari. Hal ini tampak dari sebagian pekerja beretnis Aceh tidak melaksanakan pekerjaan sesuai dengan harapan, sehingga para penyedia lapangan kerja saat ini terkesan enggan mempekerjakan orang Aceh. Dalam kaitan ini, Thamrin, pengusaha Hermes Hotel di Aceh, misalnya, menyitir salah satu sebab investor enggan berinvestasi di Aceh adalah karena adanya stigma bahwa orang Aceh itu pemalas (Serambi Indonesia, 31 Januari 2011). Selain itu, peneliti senior pada BPTP (Balai Pengkajian Teknologi Pertanian) Aceh, Chairunas (dalam Tabloid PEUDAP, 14 Januari 2011) mengeluhkan rendahnya etos kerja petani Aceh. Menurutnya, banyak petani Aceh disibukkan oleh pesta pascapanen. Akibatnya, kegiatan cocok tanam sering tertunda. Karena itu, Chairunas menyarankan agar masa istirahat pascapanen yang relatif lama dapat digunakan untuk menanam palawija, seperti kedelai benih unggul.

Stigma bahwa orang Aceh itu pemalas secara implisit telah memengaruhi cara pandang pengusaha Aceh sendiri. Cara pandang ini ditandai dengan kecenderungan mereka mendatangkan pekerja dari luar Aceh daripada mempekerjakan orang Aceh sendiri, terutama untuk pembangunan fisik gedung. Namun, dalam pandangan Iskandar (Serambi Indonesia, 3 Februari 2011) bahwa perihal rajin dan malas itu tidaklah menjadi monopoli etnis tertentu. Pernyataan-pernyataan di atas menarik dicermati, karena pada era 1950 - 1970-an perekonomian Kota Medan Sumatera Utara, misalnya, justru didominasi pedagang beretnis Aceh, terutama di bawah korporasi Aceh Sepakat dan Aceh Kongsi. Selain itu, beberapa perkebunan sawit dan karet di Langkat dan Tebing Tinggi merupakan milik orang Aceh dengan pekerja sebagian besar orang Aceh. Berbanding terbalik dengan kenyataan ini, muncul pertanyaan: mengapa sekarang ada anggapan bahwa orang Aceh itu pemalas? Jika benar mereka malas, apa sebabnya mereka menjadi pemalas?

Mencermati stigma malas yang dilabeli kepada etnis Aceh yang mengarah pada prejudis atau prasangka buruk, padahal secara filosofis ideologis orang Aceh itu harus rajin, menjadi alasan utama dilakukannya penelitian ini. Alasan lain yang mendasari penelitian ini adalah sebagai berikut. Pertama, hasil penelitian Harun (2006) menunjukkan bahwa orang Aceh sebenarnya memiliki basis filosofis-ideologis yang mapan dalam dimensi etos kerja berkarakter, yaitu berupa ajaran nenek moyang yang disampaikan melalui hadih maja, tetapi belum diformulasikan sebagai bahan ajar pendidikan karakter yang berguna untuk meningkatkan taraf hidup mereka. Kedua, orang Aceh dikenal memiliki militansi tinggi dalam mempertahankan keberlangsungan hidup (survival), baik dalam lingkup agama, sosial, budaya, maupun ekonomi (Harun, 2009). Ketiga, penelitian ini penting untuk menggugurkan stigma orang Aceh itu pemalas. Stigma ini menyebabkan hilangnya kepercayaan diri generasi muda Aceh dalam bekerja, sekaligus membuat pengambil kebijakan dalam sektor ekonomi (pemerintah dan pengusaha) kurang percaya pada tenaga kerja beretnis Aceh. Keempat, menindaklanjuti rekomendasi Seminar Pendidikan Karakter di Unsyiah, 23 November 
2012 bahwa nilai-nilai keacehan yang berkaitan dengan etos kerja berkarakter perlu dimasukkan ke dalam kurikulum muatan lokal di Aceh khususnya, terutama pada jenjang pendidikan dasar dan menengah. Merujuk beberapa alasan di atas, penelitian ini penting dilakukan. Adapun tujuan penelitian ini adalah untuk mengidentifikasi dan menafsirkan prinsip-prinsip dasar etos kerja orang Aceh dan karakteristik nilai-nilai etos kerja orang Aceh berdasarkan hadih maja sebagai bahan ajar pendidikan karakter.

\section{METODE PENELITIAN}

Penelitian ini difokuskan pada perihal etos kerja yang terkandung dalam hadih maja. Etos kerja dimaksud meliputi prinsip-prinsip dasar etos kerja dan karakteristik nilai-nilai etos kerja. Kajian tentang prinsip-prinsip dasar etos kerja bertumpu pada dimensi filosofis orang Aceh yang wajib dimiliki seseorang dalam bekerja. Sementara itu, kajian mengenai karakteristik nilai-nilai etos kerja berhubungan dengan pola nilai yang harus direpresentasikan seorang manusia Aceh dalam bekerja secara sehat dan kompetitif. Identifikasi dan penafsiran prinsip dasar dan karakteristik nilai etos kerja dalam hadih maja tersebut dilakukan dalam kerangka pendekatan kualitatif. Pendekatan kualitatif dipilih karena (1) menggunakan teks hadih maja yang bersifat alamiah, (2) peneliti sebagai instrumen kunci (Bogdan dan Biklen, 1982:2730), (3) pemaparan dan pembahasan bersifat deskriptif-interpretatif-eksplanatif (Denzin dan Lincoln, 2009:19), (4) lebih mengutamakan proses daripada hasil, (5) analisis data dilakukan secara interaktif, (6) makna menjadi perhatian utama (Lincoln \& Guba, 1985:187-219). Jenis penelitian yang digunakan adalah etnografi dengan alasan bahwa hadih maja memiliki spesifikasi etnik. Hal ini sesuai dengan hakikat penelitian etnografi yang mendeskripsikan secara analitik dan mendalam situasi budaya yang spesifik (Wuradji dalam Jabrohim, eds., 2001:6).

Sumber data penelitian ini terdiri atas (a) dokumen dan (b) informan. Sumber data dokumen adalah dokumen berisi hadih maja yang terkait dengan etos kerja, yaitu (1) buku Himponan Hadih maja (Hasyim MK, 1969); (2) Kamus Aceh Indonesia (Bakar, dkk. 1985); (3) buku Bahasa Aceh (Sulaiman, 1979); (4) Atjehsch-Nederlandsch Woordenboek (Djajadiningrat, 1934), dan (5) buku Peradaban Aceh (Umar, 2012). Informan adalah subjek penelitian dengan kriteria (1) menguasai hadih maja secara komprehensif, (2) berjenis kelamin laki-laki dan perempuan, (3) menguasai bahasa Aceh, (4) berusia di atas 30 tahun dan tidak pikun. Informan berjumlah 15 orang yang dipilih secara purposif, tersebar di Banda Aceh (2), Aceh Besar (2), Pidie (3), Aceh Utara (5), Langsa (2), dan Nagan Raya (3). Data penelitian adalah hadih maja yang terkait dengan etos kerja berkarakter dari kedua sumber data.

Data penelitian ini dikumpulkan dengan teknik kaji dokumen dan wawancara. Teknik kaji dokumen digunakan untuk mencari hadih maja dari sumber dokumen, sedangkan teknik wawancara digunakan untuk memperoleh hadih maja dari informan. Wawancara diiringi dengan rekaman dan catatan, termasuk catatan reflektif. Data dianalisis dengan teknik deskriptif kualitatif, meliputi tahap (1) analisis domain, (2) analisis taksonomi, (3) analisis komponensial, (4) penarikan simpulan, dan (5) verifikasi dengan pakar dan teman sejawat (Spradley, 1980; Miles dan Hubberman, 1990).

\section{HASIL DAN PEMBAHASAN}

\section{Hasil}

\section{Prinsip Dasar Etos Kerja Berbasis Hadih Maja}

Prinsip dasar etos kerja dalam penelitian ini dimaksudkan sebagai pokok-pokok etos kerja yang harus ada dalam diri orang Aceh dan menjadi fondasi filosofis orang Aceh memandang etos kerja. Dari hasil penelitian ini teridentifikasi 7 prinsip dasar etos kerja orang Aceh dalam hadih maja sebagaimana tertera pada tabel berikut. 
Tabel 1. Prinsip Dasar Etos Kerja Orang Aceh

\begin{tabular}{|c|c|c|}
\hline $\begin{array}{l}\text { Prinsip Dasar } \\
\text { Etos Kerja }\end{array}$ & $\begin{array}{l}\text { Sampel Hadih Maja } \\
\text { Pendukung }\end{array}$ & $\begin{array}{l}\text { Interpretasi Argumen } \\
\text { (Keyakinan Orang Aceh) }\end{array}$ \\
\hline $\begin{array}{l}\text { Bekerja sebagai } \\
\text { kewajiban } \\
\text { (terdapat dalam } 7 \\
\text { hadih maja) } \\
\end{array}$ & $\begin{array}{l}\text { Raseuki ngon tagagah } \\
\text { Tuah ngon tamita } \\
\text { (Rezeki harus diusahakan } \\
\text { Untung harus dicari) } \\
\end{array}$ & $\begin{array}{l}\text { Dalam realitas kehidupan, rezeki atau } \\
\text { harta memang wajib diusahakan dan atau } \\
\text { dicari. Rezeki tidak akan ada atau datang } \\
\text { dengan sendirinya. }\end{array}$ \\
\hline $\begin{array}{l}\text { Bekerja Mandiri } \\
\text { (terdapat dalam } 6 \\
\text { hadih maja) }\end{array}$ & $\begin{array}{l}\text { Beujeuet aneuk kahareukat } \\
\text { Laot darat pawang keudroe } \\
\text { (Pintarlah anak berusaha } \\
\text { Laut dan darat atur sendiri) }\end{array}$ & $\begin{array}{l}\text { Ungkapan laut dan darat kamu atur } \\
\text { sendiri menunjukkan kewajiban bekerja } \\
\text { secara mandiri. Ungkapan laut dan darat } \\
\text { bermakna segala sesuatu atau semua jenis } \\
\text { pekerjaan. }\end{array}$ \\
\hline \begin{tabular}{|l} 
Bekerja secara \\
totalitas \\
(terdapat dalam 2 \\
hadih maja) \\
\end{tabular} & $\begin{array}{l}\text { Ulee seumeuon } \\
\text { Baho meugulam } \\
\text { (Kepala menjunjung } \\
\text { Bahu memikul) } \\
\end{array}$ & $\begin{array}{l}\text { Kepala dan bahu diberdayakan bersama } \\
\text { bermakna bahwa dalam bekerja harus } \\
\text { memanfaatkan segala potensi yang } \\
\text { dimiliki (total). }\end{array}$ \\
\hline $\begin{array}{l}\text { Bekerja berbekal } \\
\text { ilmu } \\
\text { (terdapat dalam } 4 \\
\text { hadih maja) }\end{array}$ & $\begin{array}{l}\text { Punca phon teelan beuna } \\
\text { 'eleum'ee } \\
\text { Hoho nyang tase keureuja } \\
\text { tateum'ee } \\
\text { (Hal paling utama memiliki ilmu } \\
\text { Di mana pun berada mendapat } \\
\text { kerja) }\end{array}$ & $\begin{array}{l}\text { Dengan ilmu, ke mana pun kita pergi atau } \\
\text { di mana pun kita berada akan memperoleh } \\
\text { pekerjaan dan bermanfaat bagi kehidupan. }\end{array}$ \\
\hline $\begin{array}{l}\text { Bekerja berbasis } \\
\text { keterampilan } \\
\text { (terdapat dalam } 3 \\
\text { hadih maja) } \\
\end{array}$ & $\begin{array}{l}\text { Paleh aneuk dara hana jeuet } \\
\text { buet jaroe } \\
\text { (Celaka anak gadis tidak bisa } \\
\text { pekerjaan tangan) }\end{array}$ & $\begin{array}{l}\text { Anak gadis akan dilecehkan bila tidak } \\
\text { memiliki keterampilan atau keahlian } \\
\text { tertentu. Artinya, wanita Aceh harus } \\
\text { terampil, apalagi para prianya. }\end{array}$ \\
\hline $\begin{array}{l}\text { Bekerja demi } \\
\text { martabat } \\
\text { (terdapat dalam } \\
10 \text { hadih maja) }\end{array}$ & $\begin{array}{l}\text { Meunyo gasien meukuwien lam } \\
\text { tapeh } \\
\text { Meunyo kaya mulia bak wareh } \\
\text { (Kalau miskin terkungkung } \\
\text { dalam sampah } \\
\text { (Kalau kaya mulia dalam } \\
\text { keluarga) }\end{array}$ & $\begin{array}{l}\text { Orang miskin sering tersingkirkan dari } \\
\text { kehidupan normal. Ini ditandai dengan } \\
\text { simbol meukuwien lam tapeh yang } \\
\text { maknanya seseorang yang tidur dalam } \\
\text { tumpukan sabut kelapa (sampah) terkesan } \\
\text { hina. Sementara orang kaya jelas berharga } \\
\text { bagi sanak keluarga. }\end{array}$ \\
\hline $\begin{array}{l}\text { Bekerja secara } \\
\text { jujur } \\
\text { (terdapat dalam } 7 \\
\text { hadih maja) }\end{array}$ & $\begin{array}{l}\text { Pangkaiteuh jujur tan } \\
\text { taseumulet } \\
\text { Mudah that udep dalam usaha } \\
\text { (Berpangkal jujur dan tak } \\
\text { menipu } \\
\text { Dimudahkan hidup dalam } \\
\text { berusaha) }\end{array}$ & $\begin{array}{l}\text { Orang yang hidup dengan modal } \\
\text { kejujuran 'pangkaiteuh jujur atau tidak } \\
\text { berbohong 'tan taseumulet, orang tersebut } \\
\text { tidak mengalami hambatan dalam hidup } \\
\text { dan berusaha atau memperoleh pekerjaan. }\end{array}$ \\
\hline
\end{tabular}

\section{Karakteristik Nilai-nilai Etos Kerja Berbasis Hadih Maja}

Yang dimaksud karakteristik dalam penelitian ini adalah model atau pola nilai etos kerja yang terdapat dalam hadih maja. Nilai-nilai etos kerja yang terkandung dalam hadih maja menjadi pelengkap atau pendukung prinsipprinsip dasar etos kerja orang Aceh. Artinya, prinsip-prinsip dasar etos kerja menjadi fondasi utama yang harus ada dalam diri orang Aceh, sementara karakteristik nilai-nilai merupakan pengembangan dari prinsip-prinsip dasar tersebut. Berikut disajikan interpretasi terhadap 23 karakteristik nilai etos kerja yang terdapat dalam hadih maja. 
Tabel 2. Karakteristik Nilai-nilai Etos Kerja Orang Aceh

\begin{tabular}{|c|c|c|}
\hline $\begin{array}{c}\text { Karakteristik } \\
\text { Nilai-nilai } \\
\text { Etos Kerja } \\
\end{array}$ & $\begin{array}{l}\text { Sampel Hadih Maja } \\
\text { Pendukung }\end{array}$ & $\begin{array}{l}\text { Interpretasi Argumen } \\
\text { (Keyakinan Orang Aceh) }\end{array}$ \\
\hline $\begin{array}{l}\text { Menghargai } \\
\text { waktu } \\
\text { (terdapat } \\
\text { dalam } 4 \text { hadih } \\
\text { maja) }\end{array}$ & $\begin{array}{l}\text { Jaroe uneun 'ab bu } \\
\text { Jaroe wie kawe eungkot } \\
\text { (Tangan kanan menyulang nasi } \\
\text { Tangan kiri memancing ikan) }\end{array}$ & $\begin{array}{l}\text { Doktrin etos kerja dalam hadih maja ini } \\
\text { mengajarkan kita agar bisa memanfaatkan } \\
\text { waktu semaksimal mungkin. Dalam waktu yang } \\
\text { bersamaan kita bisa melakukan banyak hal. } \\
\text { Dalam hadih maja ini disuratkan dengan } \\
\text { 'makan nasi dan memancing ikan dilakukan } \\
\text { sekaligus'. }\end{array}$ \\
\hline $\begin{array}{l}\text { dalam } \\
\text { oat } \\
\text { oatih }\end{array}$ & $\begin{array}{l}\text { buet } \\
\text { et bak pruet } \\
\text { cari kerja } \\
\text { ada perut) }\end{array}$ & $\begin{array}{l}\text { Meskipun hadih maja ini membicarakan tentang } \\
\text { orang yang main-main dalam bekerja, tetapi } \\
\text { yang sebenarnya hendak disampaikan adalah } \\
\text { tentang perlunya keseriusan dalam berusaha. } \\
\text { Maksud tidak serius dalam bekerja tergambar } \\
\text { dalam ambil ter (bahan aspal) lumuri perut } \\
\text { menunjukkan perbuatan main-main. }\end{array}$ \\
\hline $\begin{array}{l}\text { gat } \\
\text { tau } \\
\text { at hadih }\end{array}$ & $\begin{array}{l}\text { Duek di gampong gadoh lam } \\
\text { awo } \\
\text { Tajak meuranto mudah bahagia } \\
\text { (Berdiam di kampung sibuk tak } \\
\text { jelas } \\
\text { Pergi merantau mudah } \\
\text { berbahagia) }\end{array}$ & $\begin{array}{l}\text { Hadih maja ini menekankan pada etos kerja } \\
\text { pentingnya merantau atau hijrah dalam } \\
\text { menggapai kebahagiaan. Minimnya peluang } \\
\text { kerja di kampung sendiri menjadikan orang- } \\
\text { orang berkeinginan merantau. Tentu saja setiap } \\
\text { orang menginginkan kehidupan yang jauh lebih } \\
\text { layak dan tidak ingin terus menerus hidup dalam } \\
\text { serba kekurangan. }\end{array}$ \\
\hline $\begin{array}{l}\text { Berjiwa } \\
\text { Kreatif } \\
\text { (terdapat } \\
\text { dalam } 2 \text { hadih } \\
\text { maja) }\end{array}$ & $\begin{array}{l}\text { Meunyo tatu'oh peulaku } \\
\text { Boh labu jeuet keu asoe kaya } \\
\text { Meunyo hana tatu'oh peulaku } \\
\text { Aneuk teungku jeuet keu } \\
\text { beulaga } \\
\text { (Kalau pandai kita mengolah } \\
\text { Buah labu pun jadi srikaya } \\
\text { Kalau tidak pintar kita olah } \\
\text { Anak ulama pun jadi penjahat) }\end{array}$ & $\begin{array}{l}\text { Hadih maja ini mengenai perlunya jiwa kreatif. } \\
\text { Bagi orang kreatif, buah labu pun dapat dibuat } \\
\text { menjadi srikaya yang kemudian dijadikan } \\
\text { sebagai bahan pembuatan timphan (penganan } \\
\text { khas Aceh). Sebaliknya, anak orang yang baik- } \\
\text { baik atau anak ulama bisa menjadi beulaga } \\
\text { (nakal) karena orang tuanya tidak kreatif } \\
\text { mengurus anaknya. }\end{array}$ \\
\hline $\begin{array}{l}\text { entasi } \\
\text { ktivitas } \\
\text { oat hadih }\end{array}$ & $\begin{array}{l}\text { Bek cet buleuen ngon } \\
\text { sadeuep } \\
\text { (Jangan menjolok bula } \\
\text { ujung sabit) }\end{array}$ & $\begin{array}{l}\text { Dalam konteks etos kerja, hadih maja ini ingin } \\
\text { mengingatkan generasi muda bahwa menghayal } \\
\text { yang dilambangkan dengan 'cet buleuen ngon } \\
\text { puteng sadeueb' harus dihindari dan jangan } \\
\text { dilakukan. Menghayal tanpa usaha dapat } \\
\text { melemahkan etos kerja (tidak produktif). }\end{array}$ \\
\hline $\begin{array}{l}\text { Berjiwa } \\
\text { Wiraswasta } \\
\text { (terdapat } \\
\text { dalam } 2 \text { hadih } \\
\text { maja) }\end{array}$ & $\begin{array}{l}\text { Buya krueng teudong-dong } \\
\text { Buya tamong meuraseuki } \\
\text { (Buaya sungai berdiri tegak } \\
\text { Buaya yang datang mendapat } \\
\text { rezeki) }\end{array}$ & $\begin{array}{l}\text { Etos kerja yang terkandung dalam hadih maja } \\
\text { ini terkait dengan sifat orang yang tidak mampu } \\
\text { berwiraswasta memanfaatkan potensi dan } \\
\text { peluang yang ada di daerahnya sendiri 'asoe } \\
\text { lhok' yang kemudian dilambangkan dengan } \\
\text { 'Buya krueng teudong-dong'. Pendatang yang } \\
\text { disimbolkan dengan 'Buya tamong meuraseuki' } \\
\text { mendapatkan rezeki karena mampu } \\
\text { memanfaatkan potensi dan peluang yang ada. }\end{array}$ \\
\hline $\begin{array}{l}\text { Memiliki } \\
\text { Kompetensi }\end{array}$ & $\begin{array}{l}\text { Tateupuk ie tareugam angen } \\
\text { Han peue peumeu-en kawe tan }\end{array}$ & $\begin{array}{l}\text { Pekerjaan akan sia-sia 'tareugam angen' } \\
\text { dilakukan tanpa modal 'kawe tan mata' baik }\end{array}$ \\
\hline
\end{tabular}




\begin{tabular}{|c|c|c|}
\hline & $\begin{array}{l}\text { mata } \\
\text { (Menepuk air menggenggam } \\
\text { angin } \\
\text { Jangan permainkan kail tanpa } \\
\text { mata) }\end{array}$ & $\begin{array}{l}\text { modal pengetahuan maupun modal material. } \\
\text { Untuk menjadi pekerja yang sukses tentu saja } \\
\text { harus memiliki kompetensi dalam menghadapi } \\
\text { resiko dan tantangan. Kompetensi diartikan } \\
\text { sebagai pengetahuan, keterampilan dan } \\
\text { kemampuan individu yang langsung } \\
\text { berpengaruh pada hasil. }\end{array}$ \\
\hline $\begin{array}{l}\text { Strategi } \\
\text { Berusaha } \\
\text { (terdapat } \\
\text { dalam } 2 \text { hadih } \\
\text { maja) }\end{array}$ & $\begin{array}{l}\text { Bloe siploh publoe sikureueng } \\
\text { Dalam ruweueng tacok laba } \\
\text { (Beli sepuluh jual sembilan } \\
\text { Dalam ruang mengambil laba) }\end{array}$ & $\begin{array}{l}\text { Hadih maja ini terkait dengan etos kerja } \\
\text { berusaha atau berbisnis dalam masyarakat Aceh } \\
\text { yang mengedepankan siasat atau strategi } \\
\text { berdagang. Sepintas terlihat bahwa membeli } \\
\text { dengan harga sepuluh lalu dijual dengan harga } \\
\text { sembilan merupakan tindakan merugi, karena } \\
\text { harga jual (sembilan) lebih rendah daripada } \\
\text { modal (sepuluh). Penjualan suatu produk } \\
\text { memerlukan promosi atau iklan agar produk } \\
\text { dimaksud bisa diketahui banyak orang. }\end{array}$ \\
\hline $\begin{array}{l}\text { Memiliki } \\
\text { Inisiatif } \\
\text { (terdapat } \\
\text { dalam } 2 \text { hadih } \\
\text { maja) }\end{array}$ & $\begin{array}{l}\text { Geutanyoe jak keudeh keunoe } \\
\text { Nyang bek tuwo cara tamita } \\
\text { (Kita pergi ke sana kemari } \\
\text { Yang jangan lupa carilah cara) }\end{array}$ & $\begin{array}{l}\text { Dalam kehidupan ini kita harus mencari cara } \\
\text { untuk meraih kesuksesan. Dalam kehidupan } \\
\text { bermasyarakat, berbangsa, dan bernegara } \\
\text { dibutuhkan orang-orang yang memiliki inisiatif; } \\
\text { orang yang selalu mencari cara mengubah cara } \\
\text { lama ke cara baru; mengubah tatanan sosial } \\
\text { yang kaku ke tananan yang dinamis; mengubah } \\
\text { kebiasaan bekerja manual ke bekerja secara } \\
\text { modern dengan alat canggih. }\end{array}$ \\
\hline $\begin{array}{l}\text { Berani } \\
\text { Menghadapi } \\
\text { Tantangan } \\
\text { (terdapat } \\
\text { dalam } 5 \text { hadih } \\
\text { maja) }\end{array}$ & $\begin{array}{l}\text { Nabsu keu laba dong bak binèh } \\
\text { rugoe } \\
\text { (Ingin mendapat untung } \\
\text { berdirilah di pinggir rugi) }\end{array}$ & $\begin{array}{l}\text { 'Berdiri di pinggir rugi' yang dimaksudkan } \\
\text { dalam hadih maja di atas adalah jangan takut } \\
\text { merugi. Harus ada keyakinan bahwa rugi itu hal } \\
\text { yang biasa. Jadi, seseorang yang hendak } \\
\text { berusaha jangan takut gagal, karena untung dan } \\
\text { rugi letaknya berdekatan. Ia ibarat dua sisi mata } \\
\text { uang; kalau tidak untung, tentu rugi, atau } \\
\text { kembali modal. Yang penting adalah jangan } \\
\text { sampai patah semangat; jangan sampai belum } \\
\text { apa-apa sudah mundur dari arena pertarungan } \\
\text { dagang, dan sebagainya. }\end{array}$ \\
\hline $\begin{array}{l}\text { Hidup } \\
\text { Berhemat } \\
\text { (terdapat } \\
\text { dalam } 2 \text { hadih } \\
\text { maja) }\end{array}$ & $\begin{array}{l}\text { Tangui nyang pantah } \\
\text { Tatamah bek meuganda } \\
\text { (Gunakan sesuai dengan } \\
\text { kebutuhan } \\
\text { Menambah jangan berlipat } \\
\text { ganda) }\end{array}$ & $\begin{array}{l}\text { Hadih maja ini berkenaan dengan hidup hemat. } \\
\text { Belilah apa yang dibutuhkan, bukan apa yang } \\
\text { diinginkan. Jika kita hendak membeli baju, } \\
\text { tidaklah perlu sampai lima atau tujuh potong. } \\
\text { Inilah yang dimaksud dengan menambah } \\
\text { berlipat ganda. Dengan kata lain, jika kita } \\
\text { memang perlu menambah baju baru, belilah } \\
\text { yang normal-normal saja atau 'tangui nyang } \\
\text { pantah'. }\end{array}$ \\
\hline $\begin{array}{l}\text { Kemauan } \\
\text { Bekerja Sama } \\
\text { (terdapat } \\
\text { dalam } 3 \text { hadih } \\
\text { maja) }\end{array}$ & $\begin{array}{l}\text { Ta-eu syedara ka reu-oh reu-ah } \\
\text { Tanyoe beubagah tasilak ija } \\
\text { (Melihat saudara bercucuran } \\
\text { keringat } \\
\text { Cepatlah kita menyingkap kain } \\
\text { sarung) }\end{array}$ & $\begin{array}{l}\text { Arti silak ija dalam baris kedua adalah } \\
\text { menggulung kain sarung atau dengan bahasa } \\
\text { lain melipat lengan baju untuk sama-sama } \\
\text { membantu saudara yang sedang susah payah } \\
\text { bekerja atau dalam kepayahan. Diharapkan, } \\
\text { jangan sampai seseorang hanya melihat saja } \\
\text { saudaranya yang sedang membutuhkan bantuan. }\end{array}$ \\
\hline
\end{tabular}




\begin{tabular}{|c|c|c|}
\hline \begin{tabular}{l|} 
Hidup \\
Seimbang \\
(terdapat \\
dalam 3 hadih \\
maja)
\end{tabular} & $\begin{array}{l}\text { Tangui ban laku tuboh } \\
\text { Tapajoh ban laku atra } \\
\text { (Berpakaian sesuai tubuh } \\
\text { Memakan sesuai kebutuhan) }\end{array}$ & $\begin{array}{l}\text { Pengeluaran seseorang haruslah sesuai dengan } \\
\text { pendapatan. Kebutuhan harus disesuaikan } \\
\text { dengan keberadaan materi, uang, atau harta } \\
\text { seseorang. }\end{array}$ \\
\hline $\begin{array}{l}\text { Sabar dalam } \\
\text { Berusaha } \\
\text { (terdapat } \\
\text { dalam } 2 \text { hadih } \\
\text { maja) }\end{array}$ & $\begin{array}{l}\text { Jeuneh raseuki wajeb tagagah } \\
\text { Bah pih phon payah tasaba } \\
\text { Kareuna saba le that faidah } \\
\text { Jeuet keu beureukah syupeu'at } \\
\text { pih na } \\
\text { (Semua rezeki wajib dicari } \\
\text { Walaupun susah haruslah } \\
\text { bersabar } \\
\text { Karena sabar banyak faidah } \\
\text { Jadi barakah hasil pun ada) }\end{array}$ & $\begin{array}{l}\text { Tidak ada keberhasilan yang diperoleh secara } \\
\text { instan. Keberhasilan yang hakiki diperoleh } \\
\text { melalui proses yang panjang. Kesabaran adalah } \\
\text { salah satu kunci kesuksesan seseorang dalam } \\
\text { berusaha. }\end{array}$ \\
\hline \begin{tabular}{l|} 
Menjaga \\
Kesehatan \\
(terdapat \\
dalam 2 hadih \\
maja)
\end{tabular} & $\begin{array}{l}\text { Mita raseuki takayoh-kayoh } \\
\text { Bek tuwo pajoh sihat anggeeta } \\
\text { (Cari rezeki dikayuh-kayuh } \\
\text { Jangan lupa makan agar sehat } \\
\text { badan) }\end{array}$ & $\begin{array}{l}\text { Hadih maja ini mengandung nilai etos kerja } \\
\text { betapa pentingnya kesehatan dan atau } \\
\text { kebugaran sebagai prasyarat produktivitas } \\
\text { dalam bekerja. Kesehatan kerja sangat penting } \\
\text { bagi para pekerja dan perusahaan. }\end{array}$ \\
\hline $\begin{array}{l}\text { Sportif dalam } \\
\text { Bekerja } \\
\text { (terdapat } \\
\text { dalam } 4 \text { hadih } \\
\text { maja) }\end{array}$ & $\begin{array}{l}\text { Lam useuha bek deungki } \\
\text { khianat } \\
\text { Bek iri ate watee gob na nekmat } \\
\text { (Dalam berusaha jangan dengki } \\
\text { khianat } \\
\text { Jangan iri hati jika orang } \\
\text { peroleh nikmat) }\end{array}$ & $\begin{array}{l}\text { Persaing dalam usaha hendaknya dijadikan } \\
\text { motivasi untuk terus menjadi lebih baik. Hadih } \\
\text { maja ini melarang kita bersaing secara tidak } \\
\text { sehat (khianat) terhadap sesama pebisnis. } \\
\text { Bersainglah secara sportif dan fair. }\end{array}$ \\
\hline atoh & $\begin{array}{l}\text { Meunyo geutanyoe galak keu } \\
\text { maju } \\
\text { Payah cemburu bak useuha } \\
\text { (Bila kita suka pada kemajuan } \\
\text { Mesti cemburu dalam berusaha) }\end{array}$ & $\begin{array}{l}\text { Belajar keberhasilan dan pengalaman orang lain } \\
\text { dalam berusaha sangat dianjurkan dalam hadih } \\
\text { maja ini. Kita harus cemburu (dalam arti positif) } \\
\text { terhadap kemajuan yang dicapai orang lain, } \\
\text { sehingga kita berhasil juga seperti mereka. }\end{array}$ \\
\hline $\begin{array}{l}\text { Memiliki } \\
\text { Fasilitas } \\
\text { (terdapat } \\
\text { dalam } 3 \text { hadih } \\
\text { maja) }\end{array}$ & $\begin{array}{l}\text { Bek meukat sira bak bineh jalan } \\
\text { Jitoh ujeuen caye dumna } \\
\text { (Jangan berjualan garam di } \\
\text { pinggir jalan } \\
\text { Turun hujan cair semua) }\end{array}$ & $\begin{array}{l}\text { Pedagang memerlukan fasilitas usaha berupa } \\
\text { tempat, toko, atau ruang tertentu. Yang penting } \\
\text { harus jelas tempat usahanya. Jangan sampai } \\
\text { seperti penjual garam yang tidak memiliki } \\
\text { tempat usaha, sehingga jika hujan turun, ia } \\
\text { harus pontang-panting lari menyelamatkan } \\
\text { barang dagangannya. Karena itu, dalam budaya } \\
\text { kerja orang Aceh, pedagang yang tidak } \\
\text { memiliki tempat usaha sangat dikecam. }\end{array}$ \\
\hline $\begin{array}{l}\text { Perencaanaan } \\
\text { yang matang } \\
\text { (terdapat } \\
\text { dalam } 4 \text { hadih } \\
\text { maja) }\end{array}$ & $\begin{array}{l}\text { Awai pubuet dudoe pike } \\
\text { Teulah 'oh akhe keupeue lom } \\
\text { guna } \\
\text { (Setelah dikerjakan barulah } \\
\text { dipikirkan } \\
\text { Menyesal kemudian tiada } \\
\text { berguna) }\end{array}$ & $\begin{array}{l}\text { Sesuatu yang sudah terjadi itu tidak ada } \\
\text { gunanya disesalkan. Itulah akibat yang harus } \\
\text { diterima karena tidak ada rencana yang baik. } \\
\text { Perencanaan secara baik sesuai dengan bidang } \\
\text { bekerja yang ditekuni sangat diperlukan. } \\
\text { Pikirkanlah secara matang terlebih dahulu jika } \\
\text { hendak melakukan suatu pekerjaan. }\end{array}$ \\
\hline $\begin{array}{l}\text { Disiplin } \\
\text { (terdapat } \\
\text { dalam } 2 \text { had } \\
\text { maja) }\end{array}$ & $\begin{array}{l}\text { Janji poh tujoh jak poh } \\
\text { sikureueng } \\
\text { Jareueng-jareueng tanyoe } \\
\text { meulaba } \\
\text { (Janji pukul tujuh datang pukul } \\
\end{array}$ & $\begin{array}{l}\text { Pesan hadih maja ini jelas, yaitu ketidaktepatan } \\
\text { waktu sesuai janji sebagai salah satu indikator } \\
\text { ketidakdisiplinan. Konsekuensi orang yang } \\
\text { tidak disiplin tentunya akan merugi atau tidak } \\
\text { beruntung dalam banyak hal (jareueng }\end{array}$ \\
\hline
\end{tabular}




\begin{tabular}{|c|c|c|}
\hline & $\begin{array}{l}\text { sembilan } \\
\text { Jarang-jarang kita memperoleh } \\
\text { laba) }\end{array}$ & $\begin{array}{l}\text { meulaba). Hadih maja ini merupakan } \\
\text { peringatan bagi kita bahwa disiplin merupakan } \\
\text { faktor penting dalam etos kerja. }\end{array}$ \\
\hline $\begin{array}{l}\text { Berpendirian } \\
\text { teguh } \\
\text { (terdapat } \\
\text { dalam } 2 \text { hadih } \\
\text { maja) }\end{array}$ & $\begin{array}{l}\text { Cab di batee labang di papeuen } \\
\text { Lagee ka lon kheun hanjeuet } \\
\text { meutuka } \\
\text { (Cap di batu paku di papan } \\
\text { Seperti kukatakan tidak boleh } \\
\text { bertukar) }\end{array}$ & $\begin{array}{l}\text { Hadih maja ini berkenaan dengan kuat atau } \\
\text { teguhnya pendirian seseorang. Ia yakin dengan } \\
\text { sesuatu yang dikerjakannya dan tidak gampang } \\
\text { goyah. Misalnya, seorang telah memilih sekolah } \\
\text { kejuruan sebagai lanjutan pendidikan formalnya } \\
\text { setelah SMP, maka ia akan tetap bertekad } \\
\text { melanjutkan sekolah di situ dengan segala } \\
\text { keyakinan akan berhasil. }\end{array}$ \\
\hline $\begin{array}{l}\text { Rajin Bekerja } \\
\text { (terdapat } \\
\text { dalam } 2 \text { hadih } \\
\text { maja) }\end{array}$ & $\begin{array}{l}\text { Keubeue beumeureugoh } \\
\text { Sagoe umong beumeulampoh } \\
\text { Breuh bu bek putoh } \\
\text { Rumoh tangga bek riyoh } \\
\text { (Kerbau harus menjadi gemuk } \\
\text { Sudut sawah harus menjadi } \\
\text { kebun } \\
\text { Beras dan nasi jangan terputus } \\
\text { Rumah tangga janganlah ribut) }\end{array}$ & $\begin{array}{l}\text { Hadih maja ini menekankan pada pentingnya } \\
\text { kegigihan dalam bekerja dengan memanfaatkan } \\
\text { modal yang ada. Misalnya, petani yang sedang } \\
\text { bersawah haruslah rajin merawatnya. Dia harus } \\
\text { juga memanfaatkan sudut sawahnya untuk } \\
\text { ditanami palawija. }\end{array}$ \\
\hline $\begin{array}{l}\text { Berjiwa } \\
\text { Manager } \\
\text { (terdapat } \\
\text { dalam } 3 \text { hadih } \\
\text { maja) }\end{array}$ & $\begin{array}{l}\text { Meunyo geutanyoe ureueng } \\
\text { carong } \\
\text { Bak-bak eungkong jeuet tacok } \\
\text { laba } \\
\text { (Kalau kita orang pandai } \\
\text { Dari siamang dapat mengambil } \\
\text { laba) }\end{array}$ & $\begin{array}{l}\text { Hadih maja ini menekankan pentingnya jiwa } \\
\text { manajer atau pemimpin dalam bekerja. } \\
\text { Seseorang harus pintar sehingga memiliki } \\
\text { kemampuan untuk mengurus orang yang berada } \\
\text { di bawah kepemimpinan dirinya. }\end{array}$ \\
\hline
\end{tabular}

\section{Pembahasan}

Dari data prinsip-prinsip dasar dan karakteristik nilai etos kerja terungkap bahwa di dalam hadih maja terkandung kearifan lokal (local wisdom) yang merupakan hasil dari local genius etnis Aceh. Budaya ini dilahirkan dan berkembang dalam sanubari orang Aceh beribu tahun yang lalu. Petuah-petuah tersurat dan tersirat dari hadih maja merupakan wujud kebiasaan dan perilaku keseharian orang Aceh dalam memahami dan mendoktrinasi etos kerja. Nilai yang terkandung dalam hadih maja hasil penelitian ini juga menjadi representasi pandangan dan pola pikir orang Aceh sebagai individu dan masyarakat. Mengenai waktu, misalnya, orang Aceh percaya bahwa waktu itu sangat berharga dan karena itu tidak boleh disiasiakan. Hal ini sejalan dengan pernyataan Vaswani (2004:77) bahwa waktu tidak dapat dibeli atau diperpanjang. Hanya manusia yang mampu memanfaatkan waktulah yang keluar sebagai pemenang.

Hasil penelitian ini juga menunjukkan bahwa dalam hadih maja tersirat kabar bahwa pada dasarnya orang Aceh memiliki prinsip atau pedoman bagaimana seharusnya mereka bersikap dan berperilaku dalam konteks etos kerja. Prinsip-prinsip yang wajib ditaati itulah yang telah terinternalisasi dalam darah orang Aceh sejak dahulu kala dan telah dipraktikkan berbilang abad. Artinya, jika ada klaim bahwa orang Aceh malas, tentu itu bukan generalisasi, melainkan kasuistis karena pada dasarnya orang Aceh memiliki etos kerja yang tinggi.

Kearifan lokal yang terkandung dalam hadih maja merupakan akumulasi dari pengetahuan dan kebijakan yang tumbuh dan berkembang dalam sebuah komunitas yang merepresentasikan perspektif teologis, kosmologis, dan sosiologisnya. Upaya membangun karakter generasi muda Aceh berbasis hadih maja sejak dini melalui jalur pendidikan dianggap sebagai langkah yang tepat. Sekolah merupakan lembaga formal yang menjadi peletak dasar pendidikan. Pendidikan di sekolah merupakan bagian dari sistem pendidikan nasional yang memiliki peranan yang amat penting dalam meningkatkan sumber daya manusia yang berkarakter. Melalui pendidikan di sekolah diharapkan akan menghasilkan 
sumber daya manusia yang berkualitas sesuai dengan tujuan luhur pendidikan.

Ki Hajar Dewantoro (dalam Tilaar, 1999:68) mengatakan bahwa kebudayaan (termasuk hadih maja) tidak dapat dipisahkan dari pendidikan, bahkan kebudayaan merupakan alas atau dasar pendidikan. Kebudayaan yang menjadi alas pendidikan tersebut haruslah bersifat kebangsaan. Semangat etos kerja yang terdapat dalam hadih maja pada hakikatnya tidak hanya berlaku bagi orang Aceh, tetapi juga relevan dengan semua etnik yang ada di Indonesia. Dengan demikian, hadih maja sebagai bagian dari kebudayaan haruslah hidup dan berkembang di dalam masyarakat kebangsaan Indonesia. Pendidikan memiliki kekuatan (power) untuk mewujudkan dinamisasi peri kehidupan dari seluruh aspek tujuan pendidikan dalam rangka mengangkat derajat dan harkat manusia.

Nilai-nilai etos kerja yang terkandung dalam hadih maja akan efektif dihayati oleh generasi muda bila diintegrasikan dalam pendidikan karakter berbasis budaya dalam pendidikan formal. Dalam konteks ini, hadih maja dimaknai sebagai sesuatu yang diwariskan, lalu dipelajari untuk kemudian meneruskan apa yang dipelajari itu serta mengubahnya menjadi sesuatu yang baru dan relevan dengan kekinian. Itulah inti dan hakikat dari proses pendidikan. Oleh karena itu, tugas pendidikan sebagai misi kebudayaan harus mampu melakukan proses pewarisan kebudayaan, membantu individu memilih peran sosial yang sesuai dengan karakter bangsanya, mengadopsi dan memadukan beragam budaya lain yang positif sebagai manifestasi inovasi sosial suatu bangsa yang terbuka.

Hasil penelitian ini mencerminkan jalinan hubungan fungsional antara pendidikan karakter dan kebudayaan (hadih maja). Kebudayaan mengandung sifat reflektif karena pendidikan merupakan gambaran kebudayaan yang sedang berlangsung. Pendidikan juga bersifat progresif karena pendidikan berusaha memediasi pembaharuan dan inovasi agar kebudayaan yang ada dapat berkembang. Kedua hal ini sejalan dengan tugas dan fungsi pendidikan, yakni meneruskan atau mewariskan kebudayaan serta mengubah dan mengembangkan kebudayaan tersebut untuk mencapai kemajuan kehidupan manusia. Di sinilah fungsi pendidikan karakter sebagai ikhtiar pewarisan nilai-nilai kebudayaan yang salah satunya diemban hadih maja.

Pelaksanaan pendidikan karakter berbasis hadih maja menekankan pentingnya unsur keteladanan yang disertai pula dengan upayaupaya untuk mewujudkan lingkungan sosial yang kondusif bagi para siswa, termasuk dalam keluarga, sekolah, dan masyarakat. Pelaksanaan pendidikan karakter akan lebih berkesan dalam rangka membentuk kepribadian siswa. Penyusunan kurikulum pendidikan karakter perlu memberikan penekanan yang berimbang kepada aspek nilai dan proses pengajarannya, termasuk berkonteks kearifan lokal. Selain itu, untuk menciptakan manusia Indonesia yang berkarakter, perlu penekanan yang berimbang antara aspek intelektual, aspek emosional, dan aspek spiritual siswa.

\section{SIMPULAN DAN SARAN}

Penelitian ini menghasilkan simpulan sebagai berikut. Pertama, hadih maja mengandung berbagai prinsip dasar dan karakteristik nilai etos kerja orang Aceh yang dapat dijadikan sebagai bahan ajar pendidikan karakter. Dari hasil penelitian ini terdapat 7 prinsip dasar dan 23 karakteristik nilai etos kerja dalam hadih maja. Kedua, Bahan ajar berbasis hadih maja dapat digunakan untuk meningkatkan etos kerja generasi muda sehingga kompetitif dalam dunia kerja untuk dapat meningkatkan status ekonomi yang lebih baik. Ketiga, hadih maja merupakan produk budaya yang masih digunakan dalam kehidupan sosial kemasyarakatan. Apabila etnis Aceh menginginkan ajaran leluhurnya hidup dalam jangka panjang, alternatif jawabannya adalah segera merevitalisasi hadih maja dalam kehidupan bermasyarakat, khususnya dalam dunia pendidikan.

Berdasarkan hasil penelitian ini disarankan beberapa hal berikut. Pertama, mengingat penelitian ini hanya menelaah etos kerja orang Aceh berdasarkan hadih maja, disarankan agar dilakukan penelitian lanjutan mengenai etos kerja dari sumber data selain hadih maja, seperti dalam cerita rakyat atau hikayat Aceh. Kedua, hasil penelitian ini dinilai komprehensif membicarakan etos kerja orang Aceh. Karena itu, disarankan agar hasil penelitian ini dijadikan sebagai salah satu bahan ajar pendidikan karakter pada pendidikan formal, khususnya di Aceh, khususnya pada tingkat 
sekolah menengah pertama. Ketiga, disarankan kepada Majelis Adat Aceh (MAA), Majelis Pendidikan Daerah (MPD), dan Dinas Pendidikan Aceh dan Kabupaten/Kota agar dapat menyosialisasikan hasil penelitian ini kepada masyarakat luas. Keempat, sudah saatnya dihidupkan kembali kebudayaan lokal dengan berbagai penyesuaian yang diperlukan.

\section{DAFTAR RUJUKAN}

Ara, L.K., dkk. 1995. Seulawah Antologi Sastra Aceh Sekilas Pintas. Jakarta: Intermasa.

Bakar, Aboe., dkk. 1985. Kamus Aceh Indonesia. Jakarta: Pusat Pembinaan dan Pengembangan Bahasa Depdikbud.

Bogdan, Robert dan Sari Knopp Biklen. 1982. Qualitative Research in Education: An Introduction to Theory and Method. Boston: Allyn and Bacon, Inc.

Brunvand, Jan Harold. 1968. The Study of American Folklore: an Introduction. New York: W.W. Norton \& Co Inc.

Chairunas. 2011. "Etos Kerja Petani Aceh Harus Ditingkatkan". Tabloid Peudap, Januari 2011. Banda Aceh: BPTP Aceh.

Danandjaja, James. 1997. Folklor Indonesia Ilmu Gosip, Dongeng, dan lain-lain. Jakarta: Grafiti.

Denzin, K. Norman dan Yvonna S. Lincoln. 2000. Handbook of Qualitative Research. Terjemahan Dariatno, dkk. 2009. Yogyakarta: Pustaka Pelajar.

Depdiknas. 2003. Kamus Besar Bahasa Indonesia Edisi Ketiga. Jakarta: Balai Pustaka.

Djajadiningrat, Hoesein. 1934. Atjehsch Nederlandsch Woordenboek Deel I-II. Batavia: Landsdrukkerij.

Harun, Mohd. 2006. Struktur, Fungsi, dan Nilai HadihMaja: Kajian Puisi Lisan Aceh. Malang: Disertasi Program Pascasarjana UM Malang.

Harun, Mohd. 2009. Memahami Orang Aceh. Bandung: Citapustaka Media Perintis.

Hasyim M.K. 1969. Himponan Hadih Maja. Banda Aceh: Dinas Pendidikan Dasar dan Kebudayaan Aceh.

Iskandar, Denni. 2011. "Benarkah Orang Aceh Malas?" Serambi Indonesia, 3 Februari 2011, halaman opini, Banda Aceh.

Jabrohim (Ed.). 2001. Metode Penelitian Sastra. Yogyakarta: Hanindita.
Lincoln, Y.S. dan E.G. Guba, 1985. Naturalistic Inquiry. Beverley Hill: SAGE Publication, Inc.

Miles, Matthew B. dan A. Michael Huberman. 1990. Qualitative Data Analysis. New York: Sage Publication, Inc.

Spradley, James P. 1980. Participant Observation. New York: Holt, Rinehart and Winston.

Sulaiman, Budiman. 1979. Bahasa Aceh. Banda Aceh: Pustaka Farabi.

Talsya, Teuku Alibasyah (Ed.). 1994. Adat dan Budaya Aceh Nada dan Warna. Banda Aceh: LAKA Pusat.

Tilaar, H.A.R. 1999. Pendidikan, Kebudayaan, dan Masyarakat Madani Indonesia, Strategi Reformasi Pendidikan Nasional. Bandung: Remaja Rosdakarya.

Umar, Muhammad (Emtas). 2008. Peradaban Aceh (Tamaddun) Kilasan Sejarah Aceh dan Adat. Banda Aceh: Penerbit CV Boebon Jaya.

Vaswani, J.P. 2004. A Little Book of Succes. Jakarta: PT Bhuana Ilmu Populer Kelompok Gramedia.

Webster's New Word Dictionary, 3rd College Edition. Diunduh 10 Februari 2015) 